\title{
PENGARUH MODEL PEMBELAJARAN TALKING STICK TEHADAP HASIL BELAJAR MATEMATIS SISWA SMA
}

\author{
Yeni Cahyani $^{1}$, Sowanto ${ }^{* 1}$ \\ ${ }^{1}$ Program Studi Pendidikan Matematika, STKIP Bima \\ *Email korespondensi: $\underline{\text { sowantos@gmail.com }}$
}

\begin{abstract}
ABSTRAK
Penelitian ini dilatarbelakangi oleh rendahnya hasil belajar matematika siswa kelas XI SMAN 1 Soromanti Kabupaten Bima-NTB tahun pelajaran 2020/2021. Untuk mengatasi hal tersebut, dikembangkan pembelajaran dengan talking stick dalam memfasilitasi siswa untuk meningkatkan hasil belajar matematikanya. Adapun tujuan dari penelitian ini adalah untuk mengetahui pengaruh model pembelajaran talking stick terhadap hasil belajar matematika siswa pada materi persamaan trigonometi kelas XI SMAN 1 Soromanti tahun pelajaran 2020/2021. Penelitian ini merupakan penelitian quasi eksperimen dengan desain penelitian menggunakan nonequivalent control group design (desain kelompok kontrol non-ekuivalen) dengan teknik purposive sampling. Populasi dalam penelitian ini adalah seluruh siswa kelas XI SMAN 1 Soromandi Tahun Pelajaran 2020/2021, dengan sampel dua kelas yang dipilih secara acak. Instrumen dalam penelitian ini berupa tes hasil belajar matematika siswa dalam bentuk uraian. Analisis data dilakukan dengan mengunakan uji-t dan uji nonparametrik Mann-Whitney $U$. Hasil penelitian menunjukkan terdapat pengaruh penggunaan model pembelajaran talking stick terhadap hasil belajar matematika siswa di SMAN 1 Kabupaten Bima-NTB Tahun Pelajaran 2020/2021.
\end{abstract}

Kata Kunci: talking stick, hasil belajar matematis.

\begin{abstract}
This research was motivated by the low mathematics learning outcomes of class XI students of SMAN 1 Soromanti, Bima-NTB in the academic year 2020/2021. To solve this problem, learning using talking sticks was developed to facilitate students to improve their mathematics learning outcomes. The purpose of this study was to determine the effect of the talking stick learning model on students' mathematics learning outcomes in the material of trigonometric equations for class XI SMAN 1 Soromanti in the 2020/2021 academic year. This study is a quasi-experimental research design using a nonequivalent control group design (non-equivalent control group design) with a purposive sampling technique. The population in this study were all students of class XI SMAN 1 Soromandi Academic Year 2020/2021, with a sample of two randomly selected classes. The instrument in this study was a test of students' mathematics learning outcomes in the form of descriptions. Data analysis was carried out using t-test and nonparametric Mann-Whitney $U$ test. The results showed that there was an effect of the use of the talking stick learning model on student mathematics learning outcomes at SMAN 1 Bima-NTB Academic Year 2020/2021.
\end{abstract}

Keywords: talking stick, mathematical learning outcomes.

\section{PENDAHULUAN}

Pendidikan merupakan amanah untuk mengembangkan sumber daya manusia yang dilakukan secara sistematis, praktis dan berjenjang. Penuntasan wajib belajar dan peningkatan 
mutu pendidikan merupakan prioritas dalam pembangunan pendidikan (Somantri, 2014). Dalam perspektif Pembangunan Pendidikan Nasional, pendidikan harus lebih berperan dalam membangun seluruh potensi manusia agar menjadi subyek yang berkembang secara optimal dan bermanfaat bagi masyarakat dan pembangunan nasional (Suryana, 2020). Pendidikan matematika merupakan salah satu program dalam upaya mencapai tujuan pendidikan nasional. Di era revolusi industri 4.0, kompleksitas dan semakin ketatnya persaingan dunia kerja memberikan tuntutan pada program pendidikan matematika untuk mampu mengembangkan lagi proses melalui kegiatan pembelajaran yang mampu menumbuhkembangkan kemampuan berpikir (Sowanto dkk, 2019). Guru merupakan salah satu unjuk tombak dalam pencapaian tujuan pendidikan nasional. Guru memiliki peran penting untuk membuat peserta didik berkualitas baik akademis, keahlian, kematangan emosional, moral serta spiritual (Alawiyah, 2013).

Pada era globalisasi ini, guru mempunyai peranan yang sangat besar dalam pelaksanaan pembelajaran di sekolah demi tercapainya proses belajar yang baik. Tugas dan peran guru bukan lagi sebagai pemberi informasi (transfer of knowledge), tetapi sebagai pendorong siswa belajar (stimulation of learning) agar dapat mengkonstruksi sendiri pengetahuan melalui berbagai aktivitas termasuk aspek berkomunikasi (Umar, 2012). Makhrus dkk (2019) mengungkapkan bahwa guru sebagai “Role Model” pada abad 21 harus memiliki keterampilan mengembangkan perangkat pembelajaran yang dapat memfasilitasi keterampilan berpikir kritis dan pemecahan masalah, kreativitas dan inovasi, komunikasi, dan kolaborasi. Lebih lanjut Silver dan Smith (1996: 20) mengungkapkan, tugas guru adalah: (1) melibatkan siswa dalam setiap tugas matematika; (2) mengatur aktivitas intelektual siswa dalam kelas seperti diskusi dan komunikasi; (3) membantu siswa memahami ide matematika dan memonitor pemahaman mereka.

Proses belajar dan mengajar yang dirancang guru akan mempengaruhi persepsi, minat, pengetahuan dan kemampuan siswa (Susanti dan Syam, 2017). Sebagai salah satu sumber ilmu, peran guru dalam merancang pembelajaran yang menarik dan menarik Mudah diterima siswa merupakan salah satu kunci dalam proses pembelajaran (Mulyadin, 2019). Hal senada juga diungkapkan Kusumah (2018) bahwa seorang pendidik dituntut untuk mampu berinovasi menciptakan perangkat pembelajaran yang mampu menumbuhkembangkan kemampuan anak dalam pembelajaran matematika. Oleh karenanya tidak bisa dipungkiri bahwa guru berperan 
penting dalam merancang pendidikan yang berkualitas. Salah satu indikator pendidikan berkualitas adalah perolehan hasil belajar yang maksimal oleh siswa, baik itu hasil belajar dalam bentuk kognitif, efektif maupun psikomotorik. Akan tetapi, keberhasilan belajar setiap siswa tidaklah sama antara satu dengan yang lainnya. Ada sebagian siswa yang mengalami masalah belajar, akibatnya hasil belajar yang dicapai kurang optimal. Untuk mengatasi hal tersebut, perlu ditelusuri faktor-faktor yang mempengaruhi hasil belajar siswa. Menurut Abdurrahman (2003) bahwa hasil belajar adalah kemampuan yang diperoleh siswa setelah melalui kegiatan belajar.

Usaha meningkatkan hasil belajar matematika dapat dilakukan dengan memperbaiki proses pembelajaran (Firmansyah, 2015). Selain gaya belajar yang mempengaruhi keberhasilan seorang siswa belajar matematika, ada faktor lain yaitu guru, sarana belajar, dan lingkungan belajar (Hartati, 2015). Lebih lanjut hendaknya juga perlu diperhatikan bahwa terdapat pengaruh yang signifikan antara interaksi siswa dan guru serta minat belajar terhadap hasil belajar matematika (Febriyanti dan Seruni, 2015). Guru dituntut untuk memiliki kemampuan merancang dan menggunakan strategi pembelajaran yang dapat menumbuhkan cara berfikir siswa agar menjadi lebih kritis dan kreatif guna membuat proses belajar yang berlangsung menjadi tidak monoton (Sowanto dkk, 2018). Oleh karena itu, tugas guru dalam memperbaiki proses pembelajaran hendaknya memperhatikan faktor-faktor yang dapat dilakukan untuk meningkatan hasil belajar peserta didik dengan menyiapkan strategi, metode, model dan media yang sesuai dengan materi yang akan diajarkan.

Sebagai salah satu faktor pendukung suksesnya pembelajaran, penggunaan model pembelajaran yang tepat harus menjadi perhatian guru dalam merancang pembelajaran. Tujuan diterapkannya model pembelajaran adalah untuk mempermudah peserta didik dalam memahami materi yang dipelajari sehingga perserta didik termotivasi untuk berperan aktif dalam proses pembelajaran salah satunya dengan menerapkan model pembelajaran talking stick pada proses belajar mengajar.

Model pembelajaran talking stick dapat diartikan sebagai model pembelajaran bermain tongkat, yaitu pembelajaran yang dirancang untuk mengukur tingkat penguasaan materi pelajaran oleh siswa dengan menggunakan media tongkat (Ode dalam Pour dkk, 2018). Suprijono (2010) menyatakan bahwa talking stick merupakan salah satu model pembelajaran inovatif yang berpusat pada siswa. Dalam pembelajaran tersebut menekankan partisipasih 
aktif dari siswa sehingga proses pembelajaran akan menyenangkan dan tidak menoton hanya berpusat pada guru saja. Hal ini sesuai dengan yang diungkapkan Mulyadin (2020) bahwa pemahaman siswa seharusnya ditanamkan melalui keaktifan siswa dalam pembelajaran. Talking stick termaksud salah satu model pembelajaran kooperatif. Model pembelajaran talking stick yang diawali dengan penjelasan dari guru, dan siswa diberikan kesempatan untuk mempelajari materi tersebut. Kemudian guru meminta siswa untuk menutup bukunya. Guru mengambil tongkat yang telah disiapkan sebelumnya. Tongkat tersebut diberikan kepada siswa, siswa yang menerima tersebut diwajibkan untuk menjawab pertanyaan dari guru demikian seterusnya.

\section{METODE PENELITIAN}

\section{Desain Penelitian}

Penelitian ini merupakan penelitian Quasi Experiment (eksperimen semu). Metode penelitian ini dipilih karena subjek tidak dikelompokkan secara acak, tetapi keadaan subjek diterima sebagaimana adanya (Russefendi, 2005). Pertimbangan penggunaan desain penelitian ini karena kelas yang ada sudah terbentuk sebelumnya, sehingga tidak dilakukan lagi pengelompokan secara acak. Jika dilakukan pembentukan kelas yang baru dimungkinkan akan menyebabkan kekacauan jadwal pelajaran serta dapat mengganggu efektivitas pembelajaran di sekolah. Desain yang digunakan dalam penelitian ini adalah desain kelompok kontrol non-ekuivalen (nonequivalent control group design). Creswell (2010) menyatakan bahwa untuk rancangan Quasi Experiment dengan nonequivalent pre-test and post-test control group design, kelompok eksperimen dan kelompok kontrol diseleksi tanpa prosedur acak. Kedua kelompok tersebut sama-sama memperoleh pre-test dan post-test, akan tetapi kelompok eksperimen saja yang diberikan perlakuan (treatment).

Pada penelitian ini, kelas eksperimen merupakan kelompok siswa yang mendapat talking stick dan kelas kontrol merupakan kelompok siswa yang mendapat pembelajaran biasa. Adanya kelas kontrol ini adalah sebagai pembanding, sejauh manakah terjadi perubahan akibat perlakuan terhadap kelas eksperimen. Adapun desain penelitian ini adalah sebagai berikut:

$$
\frac{\mathrm{O}}{\mathrm{O}}-\frac{\mathrm{X}}{\mathrm{O}}-\frac{\mathrm{O}}{\mathrm{O}}
$$




\section{Keterangan:}

O : Pre-test atau post-test hasil belajar matematika siswa

$\mathrm{X} \quad$ : Pembelajaran dengan talking stick

- - - : Subjek penelitian tidak dikelompokkan secara acak.

\section{Populasi dan Sampel}

Populasi dalam penelitian ini adalah seluruh siswa kelas XI SMAN 1 Soromandi yang terdiri dari 4 kelas Tahun Pelajaran 2020/2021. Adapun pertimbangan sekolah yang dipilih termasuk dalam level menengah, karena pada level menengah kemampuan akademik siswa heterogen, sehingga dapat mewakili siswa dari tingkat kemampuan tinggi, sedang dan rendah.

Pemilihan sampel penelitian ditentukan berdasarkan purposive sampling yaitu tehnik pengambilan sampel berdasarkan pertimbangan tertentu (Sugiyono, 2008). Tujuan dilakukan pengambilan sampel seperti ini adalah agar penelitian dapat dilaksanakan secara efektif dan efisien terutama dalam hal pengawasan, kondisi subjek penelitian, waktu penelitian yang ditetapkan, kondisi tempat penelitian serta prosedur perizinan. Berdasarkan teknik ini, dalam penelitian ini diperoleh sampel sebanyak dua kelas dari jumlah kelas yang ada. Satu kelas dijadikan sebagai kelas eksperimen yang pembelajarannya menggunakan talking stick dan satu kelas lainnya sebagai kelas kontrol yang pembelajarannya dengan pembelajaran biasa.

\section{Instrumen Penelitian}

Instrumen penelitian adalah alat bantu atau fasilitas yang digunakan oleh peneliti dalam pengumpulan data agar pekerjaannya lebih mudah dan hasilnya lebih baik dalam arti lebih cermat, lengkap dan sistematis sehingga lebih mudah diolah (Arikunto, 2019). Instrumen yang digunakan dalam penelitian ini yaitu berupa tes. Instrumen dalam bentuk tes berupa seperangkat soal pre-test dan post-test yang digunakan untuk mengukur hasil belajar matematika peserta didik dengan tujuan untuk mengetahui hasil belajar siswa setelah mengikuti proses pembelajaran dengan menggunakan model pembelajaran talking stick. 


\section{HASIL DAN PEMBAHASAN}

\section{Hasil penelitian}

Penelitian ini dilaksanakan di kelas XI SMAN 1 Soromanti Tahun Pelajaran 2020/2021. Siswa yang di jadikan sampel sebanyak 2 kelas yang berjumlah 40 orang, yaitu kelas Mia-1 sebanyak 20 orang (kelas eksperimen) dan Mia-2 sebanyak 20 orang (kelas kontrol).

Instrumen yang digunakan dalam penelitian ini adalah tes. Sebelum tes diujikan kepada responden maka terlebih dahulu diadakan uji coba kepada siswa kelas lain untuk mengetahui validitas tes, reliabilitas tes, daya pembeda tes dan tingkat kesukaran tes. Dari 8 butir soal yang diujikan terdapat 5 butir soal yang dinyatakan valid dan 3 butir soal yang tidak valid. Sedangkan hasil pengujian reliabilitas tes diperoleh $r_{\text {hitung }}=0,847$ yang termasuk dalam kategori reliabilitas sangat tinggi.

Setelah dilakukan uji coba, kemudian dilakukan penelitian. Penelitian yang dilakukan di kelas XI SMAN 1 Soromandi dengan menggunakan model pembelajaran talking stick pada kelas eksperimen dan pembelajaran konvensional dengan metode ceramah pada kelas kontrol. Adapun tahap penelitian yang dilalui oleh peneliti adalah melakukan pretest dan postets. Data pretes tersebut digunakan oleh peneliti untuk melakukan uji coba insterumen validitas tes, reliabilitas tes, daya pembeda tes dan tingkat kesukaran tes.

a. Analisis Data Pretest dan Posttest Hasil Belajar Matematika Siswa

Untuk mengetahui apakah model pembelajaran Talking Stick mempengaruhi hasil belajar Matematika Siswa kelas XI di SMAN 1 Soromandi terlebih dahulu dilakukan beberapa pengujian yang menjadi prasyarat sebelum data dianalisis yaitu dilakukan uji normalitas dan uji homogenitas dalam menentukan uji statistik yang akan digunakan.

\section{Pengujian Normalitas}

Pengujian normalitas dilakukan terhadap data pretest dan posttest dari masingmasing kelas yang diajarkan dengan menggunakan model pembelajara talking stick maupun kelas yang tidak diajarkan menggunakan model pembelajaran konvensional. Pengujian normalitas data digunakan untuk mengetahui apakah data tersebut berdistribusi normal atau tidak. Dengan menggunakan IMB SPSS versi 21, perhitungan rinci normalitas dari kedua kelas seperti pada tabel di bawah ini. 
Tabel 1. Pengujian Normalitas Hasil Belajar Matematika Siswa

\begin{tabular}{lccc}
\hline Kelas & \multicolumn{3}{c}{ Shapiro-Wilk } \\
\cline { 2 - 4 } & Statistic & df & Sig. \\
\hline PreTes Eksperimen & .847 & 20 & .050 \\
PostTes Eksperimen & .867 & 20 & .100 \\
PreTes Kontrol & .755 & 20 & .060 \\
PostTes Kontrol & .949 & 20 & .350 \\
\hline
\end{tabular}

Berdasarkan tabel di atas, dapat dilihat bahwa nilai Sig untuk kedua kelas baik untuk pretest maupun posttestnya adalah lebih dari nilai $\alpha$. Hal ini berarti bahwa pretest dan posttest kedua kelompok siswa yang dijadikan sampel penelitian memiliki sebaran data yang berdistribusi normal.

\section{Pengujian Homogenitas}

Uji homogenitas bertujuan untuk melihat apakah data pada kedua kelompok berasal dari populasi yang homogen. Pengujian homogenitas dilakukan pada kedua kelompok dengan taraf signifikasi yang ditetapkan adalah $\alpha=0,05$

Tabel 2. Pengujian Homogenitas Hasil Belajar Matematika Siswa

\begin{tabular}{llcl}
\hline Levene Statistic & $\mathrm{df1}$ & $\mathrm{df} 2$ & Sig. \\
\hline 1.438 & 3 & 76 & .238
\end{tabular}

Dari hasil pengujian dengan menggunakan SPSS versi 21, diperoleh nilai Sig = 0,238 , ini lebih besar dari nilai $\alpha=0,05$. Hal ini berarti bahwa kedua kelompok data bersifat homogen sehingga tidak ada perbedaan diantara keduanya dan data yang ada memiliki varians yang sama. Tidak ada perbedaan kelas yang lebih unggul daripada kelas tersebut, masing-masing kelas memiliki persamaan antara siswa yang berprestasi dan juga memiliki siswa yang kurang atau lambat dalam belajar.

\section{Pengujian Hipotesis}

Berdasarkan uji prasyarat analisis statistik diperoleh bahwa data pretest dan posttest berdistribusi normal dan homogen, sehingga pengujian dilanjutkan dengan menggunakana uji-t dengan SPSS versi 21. Uji hipotesis dilakukan pada hasil posttest kedua kelompok yaitu 
eksperimen atau kelompok yang diajar dengan menggunakan model pembelajaran talking stick dan kelompok kontrol atau kelompok kelas yang tdiajar dengan menggunakan model pembelajaran konvensional.

Adapun rincian perhitungan uji-t seperti pada rangkuman yang terdapat pada tabel di bawah ini.

Tabel 3. Pengujian Hipotesis Kelas Kontrol dan Eksperimen

\begin{tabular}{cccc}
\hline \multicolumn{2}{c}{ t-test for Equality of Means } & Keterangan \\
\cline { 1 - 2 } $\mathrm{t}$ & $\mathrm{df}$ & Sig. (2-tailed) & \\
0,540 & 38 & 0,000 & $\mathrm{H}_{0}$ ditolak. \\
\hline
\end{tabular}

Berdasarkan hasil uji statistik pada Tabel 3 diatas, diperoleh nilai Sig. (2-tailed) yaitu $0,000<\boldsymbol{\alpha}=0,05$ sehingga $\mathrm{H} 0$ ditolak. Artinya, terdapat pengaruh pembelajaran talking stick terhadap hasil belajar matematika siswa. Dengan demikian terbukti bahwa hipotesis yang menyatakan terdapat pengaruh pembelajaran talking stick terhadap hasil belajar matematika siswa di SMAN 1 Soromandi Desa Punti Kec. Soromandi Kab. Bima.

\section{Pembahasan}

Penelitian yang dilakukan di SMAN 1 Soromandi Desa Punti ini melibatkan dua kelas yaitu kelas eksperimen dan kelas kontrol. Sebelum diberi perlakuan, kedua kelas diberikan pretest terlebih dahulu untuk mengetahui kemampuan awal siswa. Adapun nilai rata-rata untuk kelas eksperimen adalah 48,35 dan untuk kelas kontrol adalah 45,05.

Setelah diketahui kemampuan awal siswa pada kedua kelas, selanjutnya siswa diberikan pembelajaran yang berbeda. Siswa pada kelas eksperimen diajarkan dengan menggunakan model pembelajaran talking stick dan siswa pada kelas kontrol tidak dengan menggunakan model pembelajaran talking stick. Disini guru menggunakan stick dan musik sebagai media sekaligus membantu siswa untuk lebih menikmati pembelajaran, senang dan merasa tidak membosankan pada saat pembelajaran berlangsung. Pada pembelajaran ini, guru menghidupkan musik lalu menjalankan stick kepada siswa secara bergiliran. Jika musik dihentikan, maka stick juga harus berhenti, dan yang terakhir memegang stick akan diberi pertanyaan oleh guru sesuai materi yang telah diajarkan.

Dengan model ini maka guru memberikan kesempatan kepada siswa untuk berani berbicara, mengemukakan pendapatnya dan siap dalam menjawab soal yang diberikan. Selain 
itu, siswa juga dapat bertanggungjawab akan apa yang dilakukannya. Karena pada pembelajaran ini jika siswa tidak mampu menjawab pertanyaan yang diberikan oleh guru, maka siswa akan diberi hukuman dengan membaca kembali materi yang diajarkan, dan diakhir pembelajaran siswa akan menjawab pertanyaan yang tidak bisa dijawab sebelumnya.

Setelah diberi perlakuan yang berbeda pada kelas eksperimen dan kelas kontrol, pada akhir pertemuan setelah materi selesai diajarkan, siswa diberikan posttest untuk mengetahui hasil belajar siswa. Adapun nilai rata-rata posttest pada kelas eksperimen adalah 85,45 sedangkan kelas kontrol adalah 77,65. Berdasarkan rata-rata nilai posttest kedua kelas, terlihat bahwa rata-rata nilai posttest kelas eksperimen lebih tinggi dibandingkan rata-rata nilai posttest kelas kontrol dengan menggunakan uji-t untuk membuktikan apakah ada pengaruh yang signifikan dan variasi hasil pembelajaran. Dari hasil yang diperoleh pada analisis inferensial menggambarkan adanya pengaruh model pembelajaran talking stick terhadap hasil belajar Matematika siswa SMAN 1 Soromandi Desa Punti. Hal tersebut terlihat pada pengujian hipotesis dengan menggunakan uji t-test sampel independen, dimana data yang diuji yaitu hasil posttest kedua kelas. Berdasarkan hasil belajar yang diperoleh dari pengujian tersebut dapat disimpulkan bahwa hasil belajar siswa meningkat setelah digunakan model pembelajaran talking stick dibandingkan pengajaran tanpa menggunakan model pembelajaran talking stick.

\section{KESIMPULAN}

Berdasarkan hasil penelitian dan pembahasan sebelumnya, maka dapat disimpulkan bahwa dengan menerapkan model pembelajaran talking stick pada pembelajaran dapat memberikan pengaruh baik pada hasil belajar matematika siswa. Setelah menggunakan model pembelajaran talking stick diperoleh rata-rata skor hasil belajar siswa di kelas eksperimen adalah 85.45 dan rata-rata skor hasil belajar untuk kelas kontrol adalah 77,65. Hal ini dibuktikan lagi oleh hasil uji hipotesis. Hasil uji hipotesis menunjukkan nilai Sig. (2-tailed) yaitu $0,000<u=0,05$ sehingga H0 ditolak. Artinya, pembelajaran talking stick berpengaruh terhadap hasil belajar matematika siswa.

\section{REFERENSI}

Abdurrahman, M. (2003). Pendidikan bagi anak berkesulitan belajar. 
Alawiyah, F. (2013). Peran guru dalam kurikulum 2013. Aspirasi: Jurnal Masalah-masalah Sosial, 4(1), 65-74.

Arikunto, S. (2019). Prosedur penelitian.

Fimansyah, D. (2015). Pengaruh Strategi pembelajaran dan minat belajar terhadap hasil belajar matematika. Judika (Jurnal Pendidikan UNSIKA), 3(1).

Febriyanti, C., \& Seruni, S. (2015). Peran minat dan interaksi siswa dengan guru dalam meningkatkan hasil belajar matematika. Formatif: Jurnal Ilmiah Pendidikan MIPA, 4(3).

Hartati, L. (2015). Pengaruh gaya belajar dan sikap siswa pada pelajaran matematika terhadap hasil belajar matematika. Formatif: Jurnal Ilmiah Pendidikan MIPA, 3(3).

Kusumah, Y. S. (2018, May). Enhancing students' mathematical representation and selfefficacy through situation-based learning assisted by geometer's sketchpad program. In Journal of Physics: Conference Series (Vol. 1013, No. 1, p. 012107). IOP Publishing.

Makhrus, M., Harjono, A., Syukur, A., Bahri, S., \& Muntari, M. (2019). Analisis Rencana Pelaksanaan Pembelajaran (RPP) terhadap Kesiapan Guru sebagai "Role Model" Keterampilan abad 21 pada Pembelajaran IPA SMP. Jurnal Penelitian Pendidikan IPA, 5(1).

Mulyadin, E. (2019, November). Developing of teaching materials for junior high school students based on ethnomathematics on traditional woven cloth (Tembe Nggoli) of Mbojo tribe. In Journal of Physics: Conference Series (Vol. 1280, No. 4, p. 042044). IOP Publishing. 
Mulyadin, E., Sowanto, S., \& Dusalan, D. (2020). Pengembangan Perangkat Pembelajaran CIRC (Cooperative Integrated Reading And Composition) dalam Meningkatkan Pemahaman Matematis Pada Materi Perbandingan Siswa SMP. SUPERMAT (Jurnal Pendidikan Matematika), 4(1), 40-51.

Gunawan, H. (2012). Pendidikan karakter. Bandung: Alfabeta, 2.

Ruseffendi, E. T. (2005). Dasar-dasar penelitian pendidikan dan bidang non-eksakta lainnya. Bandung: Tarsito.

Pour, A. N., Herayanti, L., \& Sukroyanti, B. A. (2018). Pengaruh Model Pembelajaran Talking Stick terhadap Keaktifan Belajar Siswa. Jurnal Penelitian dan Pengkajian Ilmu Pendidikan: e-Saintika, 2(1), 36-40.

Silver, E. A., \& Smith, M. S. (1996). Building discourse communities in mathematics classrooms: A worthwhile but challenging journey. Communication in mathematics, $K$ 12 and beyond, 20-28.

Somantri, M. (2014). Perencanaan pendidikan.

Sowanto, S., Andang, A., Mutmainnah, M., \& Saputra, H. A. (2019). Kemampuan SelfEfficacy Mahasiswa Melalui Bahan Ajar Metode Statistika Menggunakan Hybrid Learning Pada Tantangan Revolusi Industri 4.0. Supermat (jurnal pendidikan matematika), 3(2), 65-73.

Sowanto, S., Soeprianto, H., \& Hapipi, H. (2018). PENERAPAN MODEL PEMBELAJARAN THINK-TALK-WRITE UNTUK MENINGKATKAN AKTIVITAS DAN PRESTASI BELAJAR MATEMATIS SISWA MTS DARUL QURAN BENGKEL. SUPERMAT (JURNAL PENDIDIKAN MATEMATIKA), 2(2), 19. 
Sugiyono. (2008). Metode penelitian pendidikan:(pendekatan kuantitatif, kualitatif dan $R \&$ $D)$. Alfabeta.

Suprijono, Agus. (2010). Cooperative Learning. Yogyakarta: Pustaka Belajar.

Suryana, S. (2020). Permasalahan mutu pendidikan dalam perspektif pembangunan pendidikan. Edukasi, 14(1).

Susanti, E., \& Syam, S. S. (2017). Peran Guru dalam Meningkatkan Kemampuan Literasi Matematika Siswa Indonesia. In Prosiding dipresentasikan dalam Seminar Matematika dan Pendidikan Matematika UNY.

Umar, W. (2012). Membangun kemampuan komunikasi matematis dalam pembelajaran matematika. Infinity Journal, 1(1), 1-9. 